\title{
Effects of prostaglandin and prolactin on luteolysis and parturient behaviour in the non-pregnant tammar, Macropus eugenii
}

\author{
L. A. Hinds, C. H. Tyndale-Biscoe, G. Shaw*, T. P. Fletcher* and \\ M. B. Renfree*
}

CSIRO, Division of Wildlife and Ecology, P.O. Box 84, Lyneham, ACT 2602, Australia; and *Department of Anatomy, Monash University, Clayton, Victoria 3168, Australia

\begin{abstract}
Summary. In Exp. 1 non-pregnant female tammars were injected, on Day 26 (the day parturition would normally occur) after removal of pouch young, with saline, $200 \mu \mathrm{g}$ ovine prolactin or $5 \mathrm{mg} P G$ and changes in plasma concentrations of progesterone, prolactin, PGF-2 $\alpha$ metabolite (PGFM), oestradiol-17 $\beta$ and LH were determined. Luteolysis occurred in females treated with prolactin alone, while treatment with PG first induced a rapid rise in prolactin and subsequently a significant decrease in plasma progesterone. After prolactin treatment the oestradiol peak, oestrus and the LH surge were advanced significantly compared to the saline-treated females.

In Exp. 2 the effects of the same treatments as used in Exp. 1 were determined on Day 23 and again on Day 26 after removal of pouch young in non-pregnant females. On Day 23 both prolactin and PG induced significant elevations in plasma progesterone, but luteolysis did not occur. On Day 26 the treatments initially induced significant elevations in plasma progesterone but these were followed by luteolysis within $8-12 \mathrm{~h}$ after treatment. PG treatment induced parturient behaviour in the non-pregnant females within 3-21 min and this persisted during the period that plasma concentrations of PGFM were elevated.

The results show that $\mathrm{PG}$ induces birth behaviour and the release of prolactin, while prolactin first induces an elevation of plasma progesterone concentrations and, in the mature CL on Day 26, subsequently induces luteolysis.
\end{abstract}

Keywords: progesterone; prolactin; LH; oestradiol; PG; tammar

\section{Introduction}

In eutherian mammals there appear to be several different mechanisms for controlling luteolysis. In domestic ruminants like the sheep and cow, luteolysis is induced by a rising concentration of PGF-2 $\alpha$ of uterine origin (Thorburn et al., 1977; Liggins, 1982), while in the rat and mouse luteolysis is induced by a pre-partum pulse of prolactin (Wuttke \& Meites, 1971; Grandison \& Meites, 1972; Bridges \& Goldman, 1975). In the tammar shortly before or coincident with parturition at Day 26-27 there are peaks of prolactin and of PG, which are accompanied by rapid luteolysis (Hinds \& Tyndale-Biscoe, 1982a, b, 1985; Shaw, 1983a; Tyndale-Biscoe et al., 1983; Lewis et al., 1986). Normally there is no peak of prolactin in non-pregnant animals and progesterone declines more slowly to basal levels by Day 29 with oestrus recurring by Day 30 .

Tyndale-Biscoe et al. (1983) suggested that the prolactin peak in pregnant tammars may induce the premature luteolysis at parturition and advance the time of oestrus. When prolactin was administered on Day 26 of the non-pregnant oestrous cycle it caused a brief elevation of progesterone at $4 \mathrm{~h}$, and complete luteolysis by $12 \mathrm{~h}$ (Tyndale-Biscoe et al., 1988). Similar treatment on Day 
23 of pregnancy caused the same elevation of progesterone at $4 \mathrm{~h}$ but luteolysis did not occur and Tyndale-Biscoe et al. (1988) suggested that this could be due to an insensitivity of the corpus luteum (CL) to the luteolytic effects of prolactin at this stage.

Lewis et al. (1986) showed a large but brief pulse of $P G$ to occur between $2 \mathrm{~h}$ before and $2 \mathrm{~h}$ after parturition and in 5 tammars the fall in progesterone occurred after the peak of PG. Shaw (1983b) found that the concentrations of PGF- $2 \alpha$ and PGE in uterine tissue increased from negligible amounts on Day 23 to maximum amounts on the expected day of parturition (Day 26-27) and then declined by 1 day post partum. Lewis et al. (1986) suggested that PG rather than prolactin is the agent of luteolysis, and that the prolactin peak is associated with the initiation of lactogenesis. However, it was recognized that the prolactin peak could induce the release of PG stored in the uterus and that this could then pass to the CL, either locally by the arterio-venous anastomoses (Towers et al., 1986) or systemically, and induce luteolysis.

The present study was designed to address three questions that arose from these previous studies: (1) to resolve the respective roles of prolactin and PG in luteolysis; (2) to examine the role of prolactin in advancing the time of oestrus, the preovulatory LH surge and ovulation; and (3) to test the idea that the responsiveness of the CL to prolactin or PG matures between Day 23 and Day 26. Because the fetus influences the time of parturition and the associated hormonal events (Tyndale-Biscoe et al., 1988), non-pregnant animals have been used.

\section{Materials and Methods}

Animals. The tammars used in these experiments came from the breeding colony in Canberra, established in 1974 with stock from Kangaroo Island, and subsequently maintained at the CSIRO Division of Wildlife and Ecology. Six groups of 5 or 6 adult females in their first month of lactation after the start of the breeding season were selected and each group was held in a separate open grassy pen provided with pelleted lucerne hay and oats and water ad libitum. When frequent blood samples were being collected on Day 26 (Exp. 1) and Day 23 and Day 26 (Exp. 2), the animals were held in pens in an animal house. The 33 females had been separated from males at the previous post-partum oestrus, so that each would be carrying an unfertilized egg and have a quiescent CL (Tyndale-Biscoe \& Renfree, 1987). The day the pouch young were removed to induce synchronous reactivation of the CL was designated Day 0 . Two adult males were introduced into each pen on Day 18, and from Day 26 the animals were checked for signs of oestrus, detected by the presence of a copulatory plug in the urogenital sinus. In Exp. 1 they were checked 3 times a day and those that had not shown oestrus by Day 32 or Day 33 were killed and the reproductive tracts examined for evidence of undetected oestrus and ovulation.

Experimental design. Experiment 1 was designed to examine the role of prolactin and PG in luteolysis and the role of prolactin in advancing oestrus and ovulation. Three groups of 5 animals were injected intramuscularly at $08: 00 \mathrm{~h}$ on Day 26 (equivalent to the day of birth in pregnant tammars) with $0.5 \mathrm{ml} \mathrm{0.9 \%} \mathrm{saline} \mathrm{(Group} \mathrm{1CO),} \mathrm{or} 200 \mu \mathrm{g} \mathrm{ovine}$ prolactin (Group IPRL) or $5 \mathrm{mg}$ PGF-2 $\alpha$ (1 ml Lutalyse: Upjohn Pty Ltd, Rydalmere, NSW, Australia) (Group IPGF). Purified ovine prolactin was prepared in Canberra (Hinds, 1989).

Experiment 2 was designed to test the idea that the responsiveness of the CL to prolactin matures between Days 23 and 26. Three groups of 6 animals were injected intramuscularly at 08:00 h on Day 23 and on Day 26 with $0.5 \mathrm{ml}$ saline (Group 2CO), $200 \mu \mathrm{g}$ ovine prolactin in $0.5 \mathrm{ml}$ saline (Group 2PRL), or $5 \mathrm{mg}$ PGF-2 $\alpha$ (1 ml Lutalyse, Upjohn) (Group 2PGF). Behaviour, induced by PG treatment, was also observed.

Collection of blood samples. Blood samples were taken from the lateral tail vein, the plasma separated by centrifugation and aliquants stored frozen until assay.

In Exp. 1, on Day 26, the saline- and prolactin-injected animals (Groups ICO and 1PRL) were bled at 06:00 h, and then hourly from 09:00 to 14:00 h, then half-hourly until 18:00 h, with one final sample at 20:00 h. The PG-treated animals (Group IPGF) were bled at $06: 00 \mathrm{~h}$, then every $15 \mathrm{~min}$ from $08: 15$ to $09: 30 \mathrm{~h}$, once at 16:00 $\mathrm{h}$ and finally at $20: 00 \mathrm{~h}, \mathrm{I} 2 \mathrm{~h}$ from the start of treatment (see Fig. 1). Thereafter blood samples were taken from all animals at 8-h intervals until $24 \mathrm{~h}$ after detected oestrus or until Day 32 (see Fig. 2).

In Exp. 2 the sampling interval after treatment was decreased to define more closely the temporal relationships between the hormones (see Fig. 3). On Day 23 and again on Day 26 all animals were bled $2 \mathrm{~h}$ before injection at 08:00 h, then every $15 \mathrm{~min}$ for $2 \mathrm{~h}$, then hourly until $20: 00 \mathrm{~h}, 12 \mathrm{~h}$ from treatment, as in Exp. 1 .

Hormone assays. Hormone concentrations were determined by radioimmunoassays previously validated for the tammar. All samples of each hormone for one animal were measured in the same assay.

Progesterone was assayed according to the method of Sernia et al. (1980) with progesterone antiserum S334, provided by Dr R. I. Cox (CSIRO, Sydney, Australia). The assay sensitivity was $25 \mathrm{pg} / \mathrm{ml}$ plasma, and intra- and interassay coefficients of variation for a pool of plasma containing $180 \mathrm{pg} / \mathrm{ml}$ were $7 \%$ and $11 \%$ respectively. 
Prolactin was determined with a heterologous radioimmunoassay, validated for the tammar by Hinds \& TyndaleBiscoe (1982b), using antibody 33-9, provided by Dr A. S. McNeilly, and ovine prolactin NIH-P-S12 as standard. The limit of sensitivity was $2 \mathrm{ng} / \mathrm{ml}$ plasma, and intra- and interassay coefficients of variation for a pool of plasma containing $15 \mathrm{ng} / \mathrm{ml}$ were $6 \%$ and $10 \%$ respectively.

PGF-2 $\alpha$ metabolite was determined according to the method of Lewis et al. (1986) using standards of PGFM and PGF- $2 \alpha$ which were generously supplied by Dr G. Jenkin (Monash University, Melbourne, Australia). Dr A. P. F. Flint (Babraham, Cambridge, UK) kindly provided the antibody to PGFM (originally from Dr K. Kirton, Upjohn, Ann Arbor, MI, USA). The cross-reactivity of this antibody has been summarized by Shaw (1983a). The assay sensitivity was $50 \mathrm{pg} / \mathrm{ml}$ plasma, and the intra- and interassay coefficients of variation for a pool of plasma containing $1 \cdot 37 \mathrm{ng} / \mathrm{ml}$ were $4.0 \%$ and $7.3 \%$ respectively.

LH was determined with a double-antibody heterologous radioimmunoassay validated for the tammar by Sutherland et al. (1980), using ovine antiserum GDN-15, provided by Dr G. D. Niswender, and NIH-LH-S19 as standard. The assay sensitivity was $0.2 \mathrm{ng} / \mathrm{ml}$ and the intra- and interassay coefficients of variation for a pool of plasma containing $1.5 \mathrm{ng} / \mathrm{ml}$ were $8 \%$ and $11 \%$ respectively.

Oestradiol-17ß was measured by the method of Shaw \& Renfree (1984) validated for tammar plasma, using antiserum S6181 provided by Dr R. I. Cox. Efficiency of the extraction procedure was $92 \%$. Sensitivity of the assay was $4 \mathrm{pg} / \mathrm{ml}$. The interassay coefficients of variation were $14 \cdot 4 \%$ and $11 \cdot 2 \%$ for 2 plasma pools containing $34 \cdot 25$ and $233 \cdot 25 \mathrm{pg}$ oestradiol $-17 \beta / \mathrm{ml}$ in 4 assays. The intra-assay coefficient of variation was $5 \cdot 33 \%$.

Behavioural observations. In Exp. I the PG-injected animals (Group IPGF) were observed to adopt the birth posture, originally described for the red kangaroo (Macropus rufus) (Sharman \& Calaby, 1964; Sharman et al., 1966), which is essentially identical in the tammar (Renfree et al., 1989). In Exp. 2, therefore, detailed observations were made on the animals to determine the time each animal spent standing, lying, sitting with tail far forward between the legs (birth posture), licking and grooming of the pouch and abdomen. Observations began before injection at $08: 00 \mathrm{~h}$ and finished at 19:38 $\mathrm{h}$ when animals no longer displayed the birth posture.

Statistical analyses. Progesterone concentrations were log transformed. For each animal in Exp. 1 the value before injection was subtracted from all the subsequent values. For Exp. 2, the average of the value before and at injection on Day 23 and Day 26 was subtracted from subsequent values for each animal on the respective day. These transformed data represent the ratios of hormone concentrations after injection to the concentration before treatment, and allow for variation between animals in the initial concentration of progesterone. Significant changes in these ratios were determined by analyses of variance calculated separately for each time after injection; a rapid decrease in the ratio in sequential samples represents luteolysis. In Exp. 1 the analysis was one-way, whereas in Exp. 2 the analysis had two factors, day and hormone treatment. In the latter case two error strata were used, between treatment and between days within animals.

In Exp. 1, one-way analysis of variance was used to compare intervals from removal of pouch young to progesterone fall, oestradiol peak, oestrus and the LH peak; and intervals (hours) between these events.

\section{Results}

\section{Experiment 1}

In saline-injected females (Group 1CO), the plasma concentrations of PGFM and prolactin remained low and showed no change throughout the $12 \mathrm{~h}$ sampling period (Fig. 1a), and plasma progesterone remained at normal levels for this stage of the cycle. At $15 \mathrm{~min}$ after the prolactin injection (Group 1PRL), plasma prolactin concentration exceeded the limits of the assay and remained so for $4 \mathrm{~h}$ and then declined over the next $8 \mathrm{~h}$. No changes in plasma PGFM were detected in the period from 4 to $12 \mathrm{~h}$ after injection (Fig. Ib), but changes within $4 \mathrm{~h}$ of injection would not have been detected because no samples were collected in this period. After PG treatment (Group 1PGF), plasma PGFM concentration was markedly elevated within 15 min as was plasma prolactin, and both remained elevated for the next $1.5 \mathrm{~h}$ and were still above basal levels $8-12 \mathrm{~h}$ after treatment (Fig. 1c).

Progesterone concentrations in all animals before treatment were typical of the late luteal stage of the non-pregnant cycle $(>250 \mathrm{pg} / \mathrm{ml})$. However, by $8 \mathrm{~h}$ after injection of prolactin (Group IPRL) or PG (Group 1PGF) plasma progesterone had decreased significantly $(P<0.01$ ) and had reached basal values by $12 \mathrm{~h}(P<0.001)$, and remained so thereafter (Figs $1 \mathrm{~b}, \mathrm{c} ; 2 \mathrm{~b}, \mathrm{c})$. In salinetreated animals (Group 1CO) no change in progesterone occurred on Day 26 but in the subsequent 6 days there was a slow decline in progesterone which reached basal concentrations on Day 30 (Fig. 2a).

In the control animals (Group 1CO) peaks of plasma oestradiol-17 $\beta$, LH surges and the occurrence of oestrus were detected between $28 \cdot 3$ and 30.7 days after removal of pouch young 


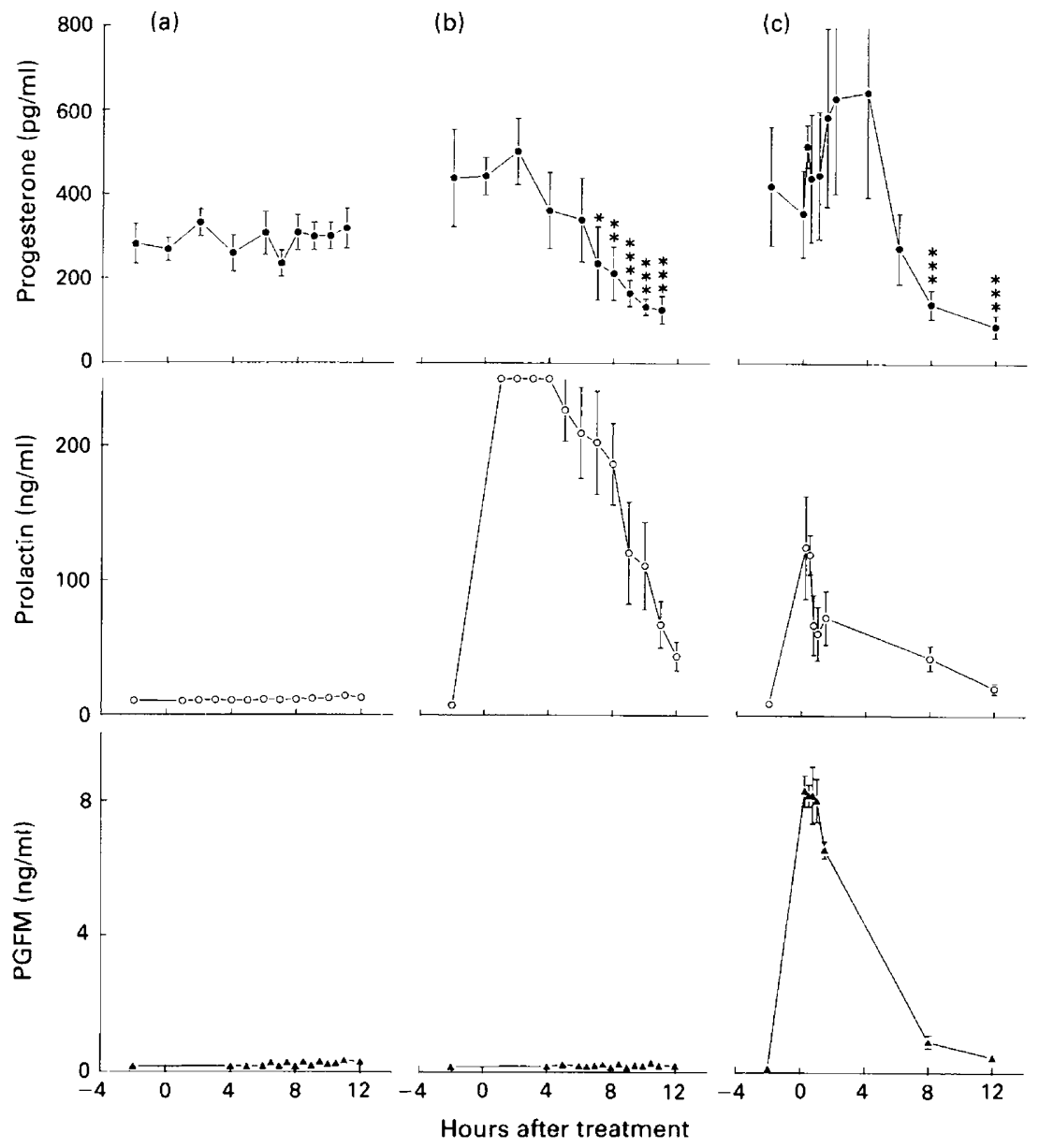

Fig. 1. Profiles of plasma progesterone $(\bullet)$, prolactin $(O)$, and PGFM $(\mathbf{\Delta})$ before and after treatment on Day 26 after removal of pouch young in animals in Exp. 1. (a) Saline-treated controls, Group 1CO, (b) prolactin treatment, Group 1PRL, and (c) PG treatment, Group 1 PGF. Values are mean \pm s.e.m. for 5 animals. ${ }^{*} P<0.05 ;{ }^{* *} P<0.01 ;{ }^{* * *} P<0.001$, compared with values of Group 1 CO.

(Fig. 2a), the normal time for non-pregnant animals (Shaw \& Renfree, 1984; Harder et al., 1985). By contrast, in prolactin-treated animals (Group 1PRL) the peaks of oestradiol-17 $\beta$ and LH occurred significantly earlier than in the control animals (oestradiol-17 $\beta, P<0.02 ; \mathrm{LH}, P<0.02$ ) (Fig. 2b). Oestrus was detected in only 2 animals and occurred 3 days earlier than in the controls. Although the decline in progesterone occurred in Group 1PGF at the same time as in Group 1PRL, no clearly defined peak of oestradiol- $17 \beta$ was detected in any animals in this group; plasma oestradiol- $17 \beta$ fluctuated between 5 and $20 \mathrm{pg} / \mathrm{ml}$ from Day 28 to Day $30 \cdot 3$. Oestrus was detected in only 2 animals and an LH peak in only 2 others (Fig. 2c), although all 5 had ovulated by Day 32 .

The interval from treatment to the LH surge in Group 1PRL was $<48 \mathrm{~h}$, which was significantly less than the interval in any animal in Group $1 \mathrm{CO}(P<0.02)$. However, the intervals from the oestradiol-17 $\beta$ peak to the LH peak were not significantly different between these two groups. A similar analysis cannot be made for Group 1 PGF. 


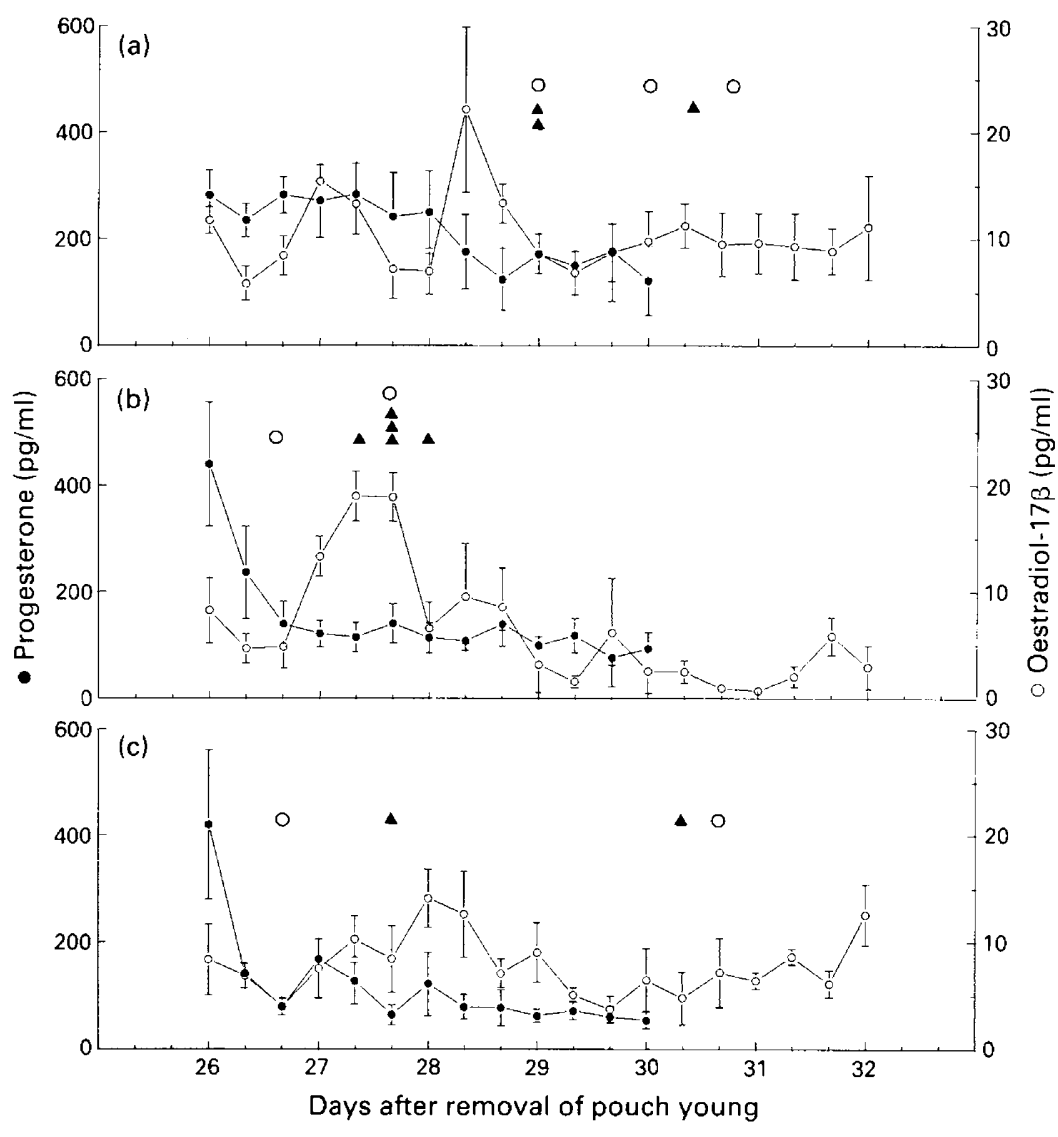

Fig. 2. Profiles of plasma progesterone $(-)$ and oestradiol-17ß $(O)$ at 8 -h intervals between Day 26 and Day 33 after removal of pouch young in females in Exp. 1. (a) Group 1CO, (b) Group 1PRL, and (c) Group 1PGF. Values are mean \pm s.e.m. for 5 animals. $\mathrm{O}=$ oestrus; $\Delta=$ LH surge.

\section{Experiment 2}

In control animals (Group 2CO) plasma progesterone concentrations were normal for this stage of the cycle in all 6 females on Day 23 and Day 26. A significant increase in plasma progesterone $(P<0.05)$ occurred in the first hour after injection of saline on both days, but the only significant decline in progesterone occurred at $12 \mathrm{~h}$ on Day $26(P<0.05)$ (Table 1) (Fig. 3a). No changes in plasma prolactin or PG were detected during the $12 \mathrm{~h}$ after treatment on Day 23 or Day 26 (Fig. 3a).

After prolactin injection (Group 2PRL) plasma prolactin was maximally elevated within 15 min and remained so for $5 \mathrm{~h}$ (Fig. 3b). On both Day 23 and Day 26 plasma PGFM was undetectable even during the first $2 \mathrm{~h}$ when samples were taken every $15 \mathrm{~min}$. Prolactin did not therefore induce a release of PGF-2 $\alpha$ at any time after treatment (Fig. 3b).

After PG injection (Group 2PGF), plasma PGFM rose to $>15 \mathrm{ng} / \mathrm{ml}$ within $15 \mathrm{~min}$ after injection and remained high for 1.75-2 h on both Day 23 and Day 26 (Fig. 3c). Thereafter it declined exponentially to basal levels by $8 \mathrm{~h}$. Prolactin was elevated in all animals within $15 \mathrm{~min}$ after injection of PG and began to decline at $4 \mathrm{~h}$ on Day 23 and $6 \mathrm{~h}$ on Day 26 (Fig. 3c). PG therefore rapidly induces the release of prolactin. 


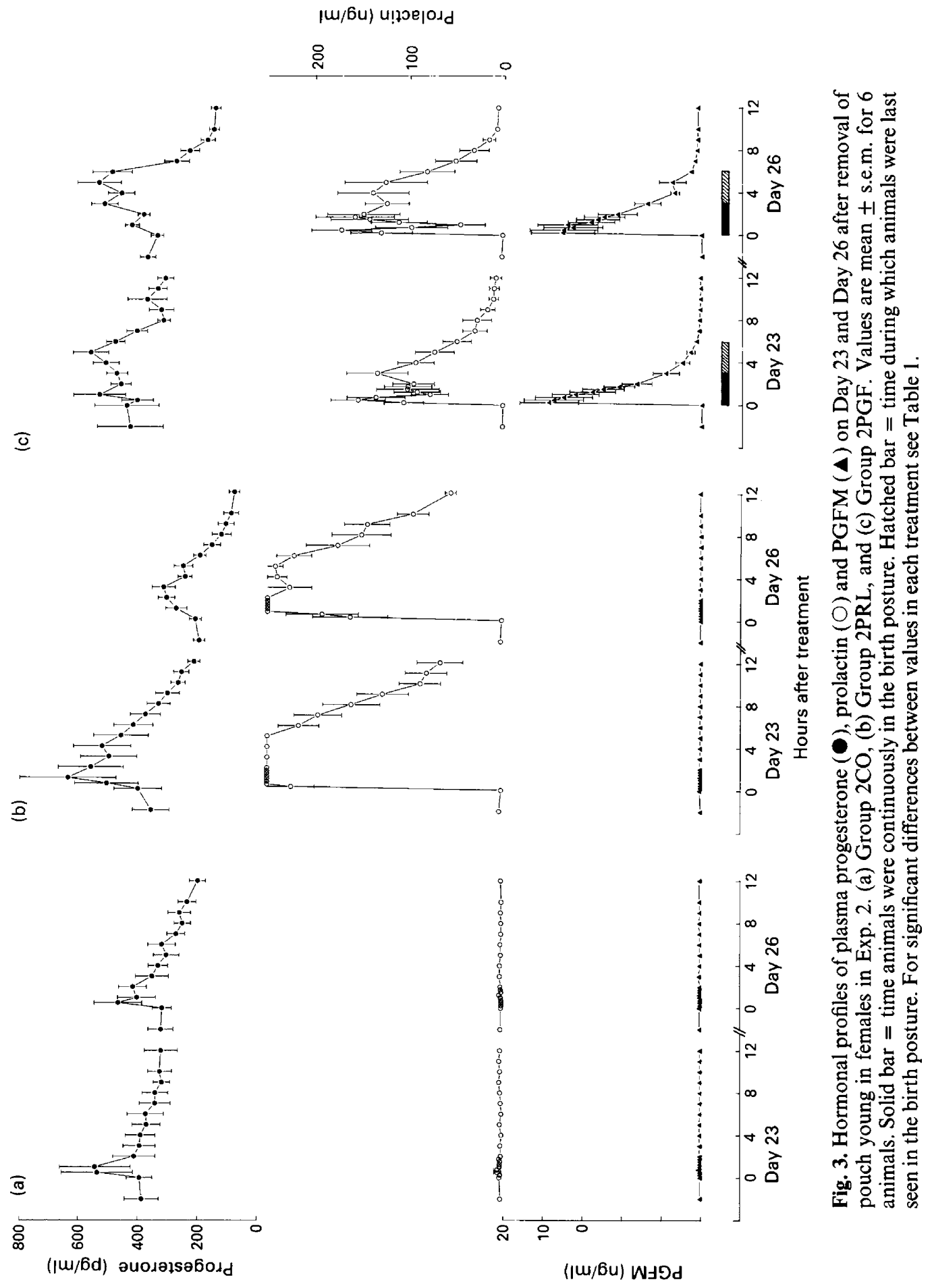


On both Day 23 and Day 26, treatment with prolactin or PG initially caused elevations of between 25 and $150 \%$ in plasma progesterone. However, the duration of and the time after treatment at which the concentrations were significantly higher than pretreatment values differed: on Day 23 a significant increase in plasma progesterone had occurred by $1-4 \mathrm{~h}(P<0.01)$ in Group 2PRL, but not until 4-5 h $(P<0.01)$ in Group 2PGF (Table 1: Fig. 3b, c). On Day 26 the rise was significant between 1 and $2 \mathrm{~h}(P<0.01)$ after prolactin (Group 2PRL), and between 2 and $5 \mathrm{~h}$ $(P<0.01)$ after PG treatment (Group 2PGF).

Table 1. Log-transformed data from Exp. 2 for progesterone concentrations after treatment with saline (Group 2CO), prostaglandin (Group 2PGF) and prolactin (Group 2PRL) expressed as the ratios between each post-treatment value and the pre-treatment value

\begin{tabular}{|c|c|c|c|c|c|c|}
\hline \multirow[b]{2}{*}{$\begin{array}{l}\text { Time } \\
\text { (h) }\end{array}$} & \multicolumn{3}{|c|}{ Day 23} & \multicolumn{3}{|c|}{ Day 26} \\
\hline & $\begin{array}{c}\text { Group } \\
2 \mathrm{CO}\end{array}$ & $\begin{array}{l}\text { Group } \\
2 \text { PGF }\end{array}$ & $\begin{array}{l}\text { Group } \\
\text { 2PRL }\end{array}$ & $\begin{array}{c}\text { Group } \\
2 \mathrm{CO}\end{array}$ & $\begin{array}{l}\text { Group } \\
2 \mathrm{PGF}\end{array}$ & $\begin{array}{l}\text { Group } \\
\text { 2PRL }\end{array}$ \\
\hline 0.5 & $1 \cdot 28^{*}$ & $1 \cdot 02 *$ & $1 \cdot 31^{* *}$ & $1.41^{* *}$ & $1 \cdot 20$ & $1 \cdot 33^{* *}$ \\
\hline 1 & $1 \cdot 32^{*}$ & $1 \cdot 32$ & $1 \cdot 60^{* * *}$ & $1 \cdot 22$ & 1.09 & $1 \cdot 52 * * *$ \\
\hline 2 & $1 \cdot 04$ & $1 \cdot 20$ & $1 \cdot 50^{* *}$ & $1 \cdot 32 *$ & $1.45^{* *}$ & $1 \cdot 55^{* *}$ \\
\hline 3 & $1 \cdot 00$ & $1 \cdot 23$ & $1 \cdot 33^{*}$ & $1 \cdot 08$ & $1 \cdot 28^{*}$ & $1 \cdot 21$ \\
\hline 4 & $1 \cdot 01$ & $1 \cdot 32^{*}$ & $1 \cdot 40^{* *}$ & $1 \cdot 05$ & $1 \cdot 46^{* *}$ & $1 \cdot 22$ \\
\hline 5 & 0.95 & $1 \cdot 43^{* *}$ & $1 \cdot 23$ & 0.94 & $1 \cdot 34^{*}$ & 0.95 \\
\hline 6 & 0.93 & $1 \cdot 25$ & $1 \cdot 14$ & 0.99 & $1 \cdot 34^{*}$ & $0.95^{*}$ \\
\hline 7 & 0.86 & 1.05 & 1.04 & $0 \cdot 86$ & $0.63^{*}$ & $0.48 * * *$ \\
\hline 8 & 0.87 & 0.82 & 0.92 & 0.79 & $0 \cdot 46^{* * *}$ & $0.44 * * *$ \\
\hline 9 & 0.84 & $0 \cdot 82$ & $0 \cdot 83$ & $0 \cdot 80$ & $0.41 * * *$ & $0 \cdot 35^{* * *}$ \\
\hline 10 & 0.84 & 0.92 & 0.75 & 0.73 & $0.40^{* * *}$ & $0.34^{* * *}$ \\
\hline 11 & 0.81 & 0.87 & 0.71 & & & \\
\hline 12 & 0.85 & 0.80 & $0.60^{* *}$ & $0.61^{*}$ & $0.39 * * *$ & $0 \cdot 30^{* * *}$ \\
\hline
\end{tabular}

Within treatments, significant changes in these ratios were determined by analyses of variance for each time after injection: ${ }^{*} P<0.05 ;{ }^{* *} P<0.01$; $* * * P<0.001$.

On Day 23 the transient elevation in plasma progesterone concentration was followed by a return to $200-300 \mathrm{pg} / \mathrm{ml}$, which was not significantly different from the initial values except at $12 \mathrm{~h}$ in Group 2PRL $(P<0.01)$ (Table 1; Fig. 3b). By contrast, on Day 26 the transient elevation in plasma progesterone was followed by a marked decline to $<100 \mathrm{pg} / \mathrm{ml}$ by $8 \mathrm{~h}$, which was significantly different from the initial values in both Group 2PRL and Group 2PGF, and from Group $2 \mathrm{CO}$ on this day $(P<0.001)$ (Table 1: Fig. 3).

\section{Behavioural observations}

None of the saline- or prolactin-treated animals (Groups 2CO and 2PRL) showed any behavioural changes after treatment, but remained alert and in a normal posture (Fig. 4a), and attempted to evade capture. However, injection of PG to Group 2PGF animals, none of which was pregnant, on both Day 23 and Day 26 induced 3 distinct behavioural changes, which we term parturient behaviour, i.e. adoption of the birth posture, docility, and panting. Within 3-21 min of injection each animal sat, often supported by the wall or fence, with its hips rotated upwards, its back hunched over and its tail drawn forward between its legs (Fig. 4b; Table 2). They groomed the lower abdomen intensely and licked vigorously around the cloaca, inside the pouch, and the fur between the two. They continued in this extreme parturient-like behaviour for about $1 \mathrm{~h}$, making no attempt to avoid capture for blood sampling, and, within seconds of being released into the pen after a bleed, they resumed this characteristic posture and grooming. Some even attempted to 

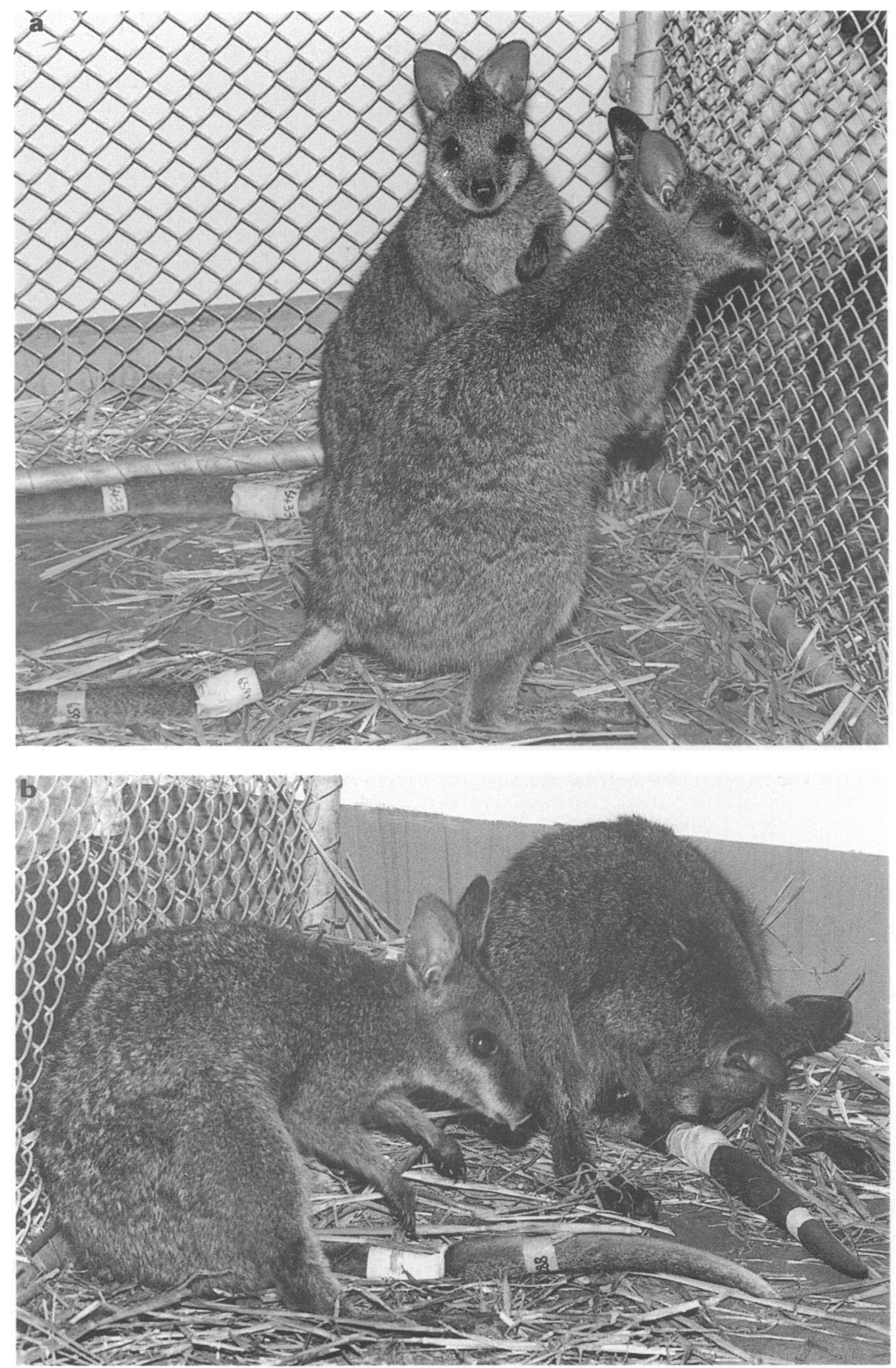

Fig. 4. Photograph of (a) 2 females in Group $2 \mathrm{CO}$, showing normal standing posture during the first hour after treatment with saline and (b) 2 females sitting in the birth posture during the first hour after treatment with PG (Group 2PGF). 
Table 2. Observations (min from treatment) of tammars in Group 2PGF on Day 23 and Day 26 after removal of their pouch young

\begin{tabular}{|c|c|c|c|c|c|c|c|c|}
\hline \multirow[b]{2}{*}{ Day } & & \multicolumn{6}{|c|}{ Animal no. } & \multirow[b]{2}{*}{ Mean \pm s.e.m } \\
\hline & & 6162 & 6238 & 6288 & 6366 & 6473 & 6475 & \\
\hline \multirow[t]{3}{*}{23} & $\begin{array}{l}\text { First seen in } \\
\text { birth posture }\end{array}$ & 20 & 4 & 17 & 16 & 10 & 21 & $14.7 \pm 2.7$ \\
\hline & $\begin{array}{l}\text { First out of } \\
\text { birth posture }\end{array}$ & 218 & 256 & 124 & 105 & 252 & 179 & $189 \pm 26$ \\
\hline & $\begin{array}{l}\text { Last seen in } \\
\text { birth posture }\end{array}$ & 218 & 352 & 129 & 197 & 288 & 293 & $246 \pm 33$ \\
\hline \multirow[t]{3}{*}{26} & $\begin{array}{l}\text { First seen in } \\
\text { birth posture }\end{array}$ & 3 & 5 & 7 & 7 & 3 & 11 & $6 \pm 1 \cdot 2$ \\
\hline & $\begin{array}{l}\text { First out of } \\
\text { birth posture }\end{array}$ & 199 & 166 & 265 & 196 & 318 & 165 & $218 \pm 25$ \\
\hline & $\begin{array}{l}\text { Last seen in } \\
\text { birth posture }\end{array}$ & 227 & 279 & 231 & 224 & 351 & 228 & $256 \pm 21$ \\
\hline
\end{tabular}

resume this posture inside the hessian bags in which they were held. This period of intense behaviour coincided with the maximum elevation of PGFM (Fig. 3c).

As the concentrations of plasma PGFM declined the animals became more alert and their behaviour gradually reverted to the preinjection behaviour: the upward rotation of the hips became less extreme; the intensity of grooming decreased, with increasing periods spent not grooming; and eventually changing between sitting with the tail forward and standing with the tail behind. Animals were first seen out of the birth posture at $3 \mathrm{~h}$ on Day 23 and $3.5 \mathrm{~h}$ on Day 26 and last seen in the birth posture at $6 \mathrm{~h}$ (Table 2: Fig. 3c).

The animals in Group 2PGF also showed a tendency to panting respiration. This was most pronounced for the first $2-3 \mathrm{~h}$ and became progressively less obvious after that.

\section{Discussion}

We conclude from these experiments that PFG- $2 \alpha$ is not directly luteolytic in the tammar, but that PGF-2 $\alpha$ rapidly induces a pulse of prolactin which is luteolytic. Since it has been shown that the conceptus is associated with the peripartum prolactin peak (Tyndale-Biscoe et al., 1988) the present results suggest that the fetus or its membranes induces this by initiating the release of PGs, which are known to occur in the endometrium and myometrium on Day 25 and 26 (Shaw, 1983b). It is not clear how this is achieved, but there is evidence that the full term fetus can secrete corticosteroids (Catling \& Vinson, 1976). Since glucocorticoids stimulate PG synthesis by human amniotic cells (Potestio et al., 1988), it is possible that corticosteroids secreted by the tammar fetus stimulate the release of PG from the placenta or endometrium by a similar mechanism, which then acts on the hypothalamus or pituitary to stimulate prolactin secretion. The prolactin peak then induces a transient rise in peripheral progesterone concentrations which is followed by a rapid decline to basal levels, and we conclude that these effects are mediated through the CL. From the present study it is not clear whether the transient rise in plasma progesterone reflects increased progesterone synthesis and/or increased depletion of luteal tissue progesterone stores.

The present results support the idea that the sensitivity of the CL to the luteolytic effect of prolactin matures during the last 3 days of pregnancy; the tammars exposed to prolactin on Day 23 (Groups 2PRL and 2PGF) showed only a transitory rise in progesterone but no subsequent fall, whereas on days 26 the transient rise was followed by luteolysis. The amplitude of the prolactin peak at the end of the cycle was similar to the daily pulse of prolactin that has been shown to inhibit 
the development of the quiescent CL during seasonal quiescence (Hinds, 1989) but the duration of the peripartum peak is longer. Prolactin therefore appears to have several roles in the control of luteal cell function; at the beginning it blocks the developmental pathway leading to hypertrophy and hyperplasia, while at the end it is first luteotrophic and then luteolytic.

An unexpected result of the study was that PG induces parturient behaviour in tammars. None of the animals used in these experiments was pregnant and yet all of those treated with PG adopted the birth posture within a few minutes and remained in it until the PG in the circulation returned to basal values. PG induces myometrial contractions in the tammar (Shaw, 1983b) and so the adopted birth posture and associated behaviour could have been a response to these contractions. Alternatively, PG may act centrally and this has been confirmed in subsequent experiments (Shaw, 1990). PGs are known to affect reproductive behaviour in fish, reptiles and mammals (Tokarz \& Crews, 1981; Whittier \& Crews, 1986) but have not previously been reported to induce parturient behaviour in mammals.

Oestrus occurs within $8 \mathrm{~h}$ of parturition in the tammar, coincident with elevated oestradiol concentrations (Shaw \& Renfree, 1984; Harder et al., 1985), which also induce the LH surge and ovulation. It is therefore of some interest that parturient behaviour and oestrous behaviour in this species are each predominantly induced by the hormone that controls the associated physiological event. Tyndale-Biscoe et al. (1983) suggested that the prolactin peak at the end of pregnancy might also precipitate post-partum oestrus and ovulation. In the present Exp. 1 the group treated with prolactin showed oestrus and ovulated significantly earlier and more synchronously than did the control group. Nevertheless, these effects cannot be due to the premature luteolysis induced by the prolactin peak since pregnant tammars from which the corpus luteum was excised on Day 23 gave birth and had a post-partum oestrus at the normal time (Harder et al., 1985). We must conclude that the prolactin peak acts either on the Graafian follicle to advance its maturation or at the hypothalamus to stimulate release of FSH. Thus the maturing fetus appears to precipitate the whole sequence of birth, oestrus and ovulation; the fetus, possibly by corticosteroids, induces release of PG, which, as shown here, induces parturient behaviour and prolactin release. Prolactin causes luteolysis and it independently advances the rise in blood oestradiol concentrations, postpartum oestrus, the LH surge and ovulation.

We thank John Wright for expert technical assistance with blood sampling and hormone assays; J. Merchant, K. Newgrain, L. Eagles and R. Joseph for assistance with collection of the numerous blood samples; and Dr J. Wood, CSIRO Biometrics Unit for the statistical analyses. This study was in part supported by ARGS Program Grant A1851504P.

\section{References}

Bridges, R.S. \& Goldman, B.D. (1975) Ovarian control of prolactin secretion during late pregnancy in the rat. Endocrinology 97, 496-498.

Catling, P.C. \& Vinson, G.P. (1976) Adrenocortical hormones in the neonate and pouch young of the tammar wallaby, Macropus eugenii. J. Endocr. 69, $447-448$.

Grandison, L. \& Meites, J. (1972) Luteolytic action of prolactin during the estrous cycle of the mouse. Proc. Soc. exp. Biol. Med. 140, 323-325.

Harder, J.D., Hinds, L.A., Horn C.A. \& Tyndale-Biscoe, C.H. (1985) Effects of removal in late pregnancy of the corpus luteum, Graafian follicle or ovaries on plasma progesterone, oestradiol, LH, parturition and post-partum oestrus in the tammar wallaby, Macropus eugenii. J. Reprod. Fert. 75, 449-459.

Hinds, L.A. (1989) Morning pulse of prolactin maintains seasonal quiescence in the tammar, Macropus eugenii. J. Reprod. Fert. 87, 735-744.
Hinds, L.A. \& Tyndale-Biscoe, C.H. (1982a) Plasma progesterone levels in the pregnant and nonpregnant tammar, Macropus eugenii. J. Endocr. 93, 99-107.

Hinds, L.A. \& Tyndale-Biscoe, C.H. (1982b) Prolactin in the marsupial, Macropus eugenii, during the estrous cycle, pregnancy and lactation. Biol. Reprod. 26, 391-398.

Hinds, L.A. \& Tyndale-Biscoe, C.H. (1985) Seasonal and circadian patterns of circulating prolactin during lactation and seasonal quiescence in the tammar, Macropus eugenii. J. Reprod. Fert. 74, 173-183.

Lewis, P.R., Fletcher, T.P. \& Renfree, M.B. (1986) Prostaglandin in the peripheral plasma of tammar wallabies during parturition. J. Endocr. 111, 103-109.

Liggins, G.C. (1982) The fetus and birth. In Reproduction in Mammals, 2nd edn, Book 2. Embryonic and Fetal Development, pp. 114-141. Eds C. R. Austin \& R. V. Short. Cambridge University Press. 
Potestio, F.A., Zakar, T. \& Olson, D.M. (1988) Glucocorticoids stimulate prostaglandin synthesis in human amnion cells by receptor-mediated mechanism. J. clin. Endocr. Metab. 67, 1205-1210.

Renfree, M.B., Fletcher, T.P., Blanden, D.R., Lewis, P.R., Shaw, G., Gordon, K., Short, R.V., Parer-Cook, E. \& Parer, D. (1989) Physiological and behavioural events around the time of birth in macropodid marsupials. In Kangaroos, Wallabies and Rat Kangaroos, pp. 323-337. Eds P. Jarman, I. D. Hume \& G. Grigg. Surrey Beatty and Sons Pty Ltd, Sydney.

Sernia, C., Hinds, L. \& Tyndale-Biscoe, C.H. (1980) Progesterone metabolism during embryonic diapause in the tammar wallaby, Macropus eugenii. J. Reprod. Fert. 69, 139-147.

Sharman, G.B. \& Calaby, J.H. (1964) Reproductive behaviour in the red kangaroo Megaleia rufa, in captivity. CSIRO Wildl. Res. 9, 58-85.

Sharman, G.B., Calaby, J.H. \& Poole, W.E. (1966) Patterns of reproduction in female diprotodont marsupials. Symp. zool. Soc. Lond. 15, 205-232.

Shaw, G. (1983a) Effect of $\mathrm{PGF}_{2 \alpha}$ on uterine activity, and concentrations of 13,14-dihydro-15-keto-PGF ${ }_{2 a}$ in peripheral plasma during parturition in the tammar wallaby (Macropus eugenii). J. Reprod. Fert. 69, $429-436$.

Shaw, G. (1983b) Pregnancy after diapause in the tammar wallaby, Macropus eugenii. Ph.D. thesis, Murdoch University, Western Australia.

Shaw, G. (1990) Control of parturient behaviour by prostaglandin F-2 $\alpha$ in the tammar wallaby, Macropus eugenii. J. Reprod. Fert. 88, 335-342.

Shaw, G. \& Renfree, M.B. (1984) Concentrations of oestradiol- $17 \beta$ in plasma and corpora lutea throughout pregnancy in the tammar, Macropus eugenii. $J$. Reprod. Fert. 72, 29-37.
Sutherland, R.L., Evans, S.M. \& Tyndale-Biscoe, C.H. (1980) Macropodid marsupial luteinising hormone: validation of assay procedures and changes in plasma levels during the oestrous cycle in the female tammar wallaby (Macropus eugenii). J. Endocr. 86, $1-12$.

Thorburn, G.D., Challis, J.R.C. \& Currie, W.B. (1977) Control of parturition in domestic animals. Biol. Reprod. 16, 18-27.

Tokarz, R.R. \& Crews, D. (1981) Effects of prostaglandins on sexual receptivity in the female lizard, Anolis carolinensis. Endocrinology 109, 451-457.

Towers, P.A., Shaw G. \& Renfree, M.B. (1986) Urogenital vasculature and local steroid concentrations in the uterine branch of the ovarian vein of the female tammar wallaby (Macropus eugenii). J. Reprod. Fert. 78, $37-47$.

Tyndale-Biscoe, C.H. \& Renfree, M.B. (1987) Reproductive Physiology of Marsupials. Cambridge University Press.

Tyndale-Biscoe, C.H., Hinds, L.A., Horn, C.A. \& Jenkin, G. (1983) Hormonal changes at oestrus, parturition and post-partum oestrus in the tammar wallaby (Macropus eugenii). J. Endocr. 96, 155-161.

Tyndale-Biscoe, C.H., Hinds, L.A. \& Horn, C.A. (1988) Fetal role in the control of parturition in the tammar, Macropus eugenii. J. Reprod. Fert. 82, 419-428.

Whittier, J.M. \& Crews, D. (1986) Effects of prostaglan$\operatorname{din} \mathrm{F}_{2 a}$ on sexual behaviour and ovarian function in female garter snakes (Thamnophis sirtalis parietalis). Endocrinology 119, 787-792.

Wuttke, W. \& Meites, J. (1971) Luteolytic role of prolactin during the estrous cycle of the rat. Proc. Soc. exp. Biol. Med. 137, 988-991.

Received 2 June 1989 